Published in final edited form as:

Lancet. 2007 October 27; 370(9597): 1471-1474. doi:10.1016/S0140-6736(07)61619-5.

\title{
Global health governance and the World Bank
}

\author{
Jennifer Prah Ruger
}

\section{Abstract}

With the Paul Wolfowitz era behind it and new appointee Robert Zoellick at the helm, it is time for the World Bank to better define its role in an increasingly crowded and complex global health architecture, says Jennifer Prah Ruger, health economist and former World Bank speechwriter.

Just 2 years after taking office as president of the World Bank, Paul Wolfowitz resigned amid allegations of favouritism, and is now succeeded by Robert Zoellick. Many shortcomings marked Wolfowitz's presidency, not the least of which were a tumultuous battle over family planning and reproductive health policy, significant reductions in spending and staffing, and poor performance in implementing health, nutrition, and population programmes. Wolfowitz did little to advance the bank's role in the health sector. With the Wolfowitz era behind it and heightened scrutiny in the aftermath, the World Bank needs to better define its role and seize the initiative in health at both the global and country levels. Can the bank have an effect in an increasingly plural and complex global health architecture? What crucial role can the bank play in global health governance in the years ahead?

\section{Global health architecture}

The international attention, levels of development assistance, and number of global health organisations, initiatives, and foundations now focused on global health are unprecedented. In the mid-1950s following the creation of the UN and WHO, there were few global actors with political or financial authority to influence global agendas. WHO, the Rockefeller Foundation, UNICEF, and, in the past few decades, the World Bank, heavily influenced global health priorities for policy and investment. In an increasingly globalising world, however, a new international health architecture has emerged, no longer dominated by a few organisations but consisting of many global health actors. The Global Fund to Fight AIDS, Tuberculosis and Malaria, Global Alliance for Vaccines and Immunization, the Bill and Melinda Gates Foundation, UNITAID (International Drug Purchase Facility), and many other players are now at work, in addition to bilateral aid such as the US President's Emergency Plan for AIDS Relief. Global financial investments in health doubled in the past 5 years from US\$6 billion in 2000 to nearly $\$ 14$ billion in 2005 .

A more in-depth look suggests an exciting new environment-but with many caveats. Much of this spending, for example, goes not to countries or individuals, but to consultants in donor countries. Debt relief accounts for a substantial portion of the recent increase in aid. Much of it also goes to other types of humanitarian assistance, is focused on specific diseases, or occurs as bilateral aid to specific countries for foreign policy reasons. Additionally, results on the ground are often mixed; lower-income countries are relying 
more heavily on external assistance; aid frequently does not support health systems or government priorities; and aid efforts are unpredictable, short-term or medium-term, and unsynchronised, among donors. And despite efforts towards global health partnerships, including the most recent International Health Partnership, global health governance remains fragmented, uncoordinated, and donor driven.

\section{The bank's health strategy}

In this complex climate, the World Bank has been forced to rethink its role in global health. As a first step, the bank recently completed a strategic planning process culminating in a new strategy for Health, Nutrition, and Population, to sharpen the bank's focus on results.

The strategy concentrates the bank's contributions on areas in which it commands a comparative advantage and exercises selectivity in engagement with global partners. Through this strategic process, the bank has rightly identified inter-sectoral country assistance; health-system strengthening; health financing and financial protection; economics; financial sustainability in the health sector; sound macroeconomic and fiscal policy; regulatory frameworks for the health sector; and good governance, accountability, and transparency in the health sector as areas in which it has strengths to generate knowledge, provide policy and technical advice, and funding.

In strengthening health systems, the strategy identified several key foci: financing, a regulatory framework for private-public collaboration, governance, insurance, logistics, provider payment and incentive mechanisms, information, well trained personnel, basic infrastructure, and supplies. The strategy underscores collaborative division of labour with global partners and leaves areas such as technical aspects of disease control (eg, drugs and treatment options for malaria or malnutrition or HIV/AIDS), human resource training in health, and internal organisation of service providers (eg, clinics and hospital services) to other organisations, particularly WHO, UNICEF, and the UN Population Fund.

On paper, the new bank strategy is sensible and parsimonious. It does not promise too much or too little. It focuses on selectivity, building on the bank's areas of health-systems expertise. The strategy also leverages the bank's special strengths as a development institution with a bird's-eye perspective on nations, working in multiple areas to reduce poverty through inter-sectoral country assistance. It underscores the bank's role in generating and disseminating knowledge and best practices through its technical assistance and policy advice; these bank features distinguish it from commercial banks, other aid sources, and even some development banks.

In short, on paper, the new strategy offers promise for a future bank role in global health. For the bank to have a real effect on the ground and achieve results in the health sector, however, it will need to focus much more on the political economy of health in developing countries; on a better understanding of policy reform in countries; on how policy decisionmaking is borne out; and on how policy actions for change occur. 


\section{An alternative approach}

The unprecedented level of financial development assistance flowing from developed to developing countries today results from many factors, not least of which is the humanitarian impulse to aid those in need. Humanitarianism is a welcome change from the seemingly careless apathy of previous decades, but it has produced many diffuse and uncoordinated initiatives focused on specific diseases. It has also widened the enormous gap between functioning and failing health systems and exacerbated weaknesses in public-health and health-care infrastructure. A theoretical and conceptual framework focused on the political economy of health offers an alternative paradigm for the bank's work in the years ahead.

A political economy of health approach focuses on the social production of health and disease, particularly on an analysis of the political and economic determinants of health and disease within a society, national, and/or global. The underlying premise is that political and economic institutions and policies either reinforce or, by reform, reduce inequalities in health. Second, this approach focuses on structural barriers and structural interventions that either impede or facilitate people's opportunities to be healthy. Third, a crucial compass embedded in this approach is an analysis of the flow, distribution, and regulation of financial and other types of capital within society and of the benefits and costs of health-related policies and programmes. Fourth, this framework's reforms target the distribution and management of resources and power in the economy and the oversight role of the government. They focus on both incremental and large-scale public efforts to effectuate change in and beyond the health sector. Fifth, equity is key.

There are at least three crucial areas where the bank can help countries strengthen health systems through a political economy of health approach. It can (1) help countries grow their economies equitably; (2) help countries establish good governance in the public and health sectors; (3) aid countries with health-policy reform.

\section{A strong economy for health}

Although there are some notable exceptions, strong health systems require sufficient financial, human, and physical capital, all of which are more likely to increase and be of good quality in stronger economies.

As countries' economies grow and they become richer, they are able to mobilise more revenues through formal sector employment and improved tax administration. Low-income countries, for example, raise only $17 \%$ of their gross domestic product (GDP) in revenues, and they spend only $\$ 55$ billion annually on health care. Moreover, about $75 \%$ of health spending is private and out of pocket. Social insurance constitutes less than $2 \%$ of total spending. External assistance accounts for 15\% of all health spending in Africa and 30\% of all health spending in 30 African countries. External assistance is about $55 \%$ of all money flowing into Africa. Low-income countries need greater GDP and a significantly larger formal employment sector; they need to mobilise greater amounts of GDP to help finance health care. 
Countries need to be able to raise money through taxes to support health systems; tax revenues derive from income and wealth generated in the economy. These are essential cornerstones of successful health-system development. Of all global health institutions, the bank is in a unique position to help countries to grow their economies equitably, but it must pay important attention to the equity implications of its economic policy advice and lending, so as not to repeat the mistakes of earlier structural adjustment programmes.

\section{Good governance for health}

Political and economic institutions are crucial for population wellbeing and health, but they cannot function effectively in the context of poor governance. Although good governance in the health sector is essential, the quality of governance overall matters as well. Can citizens participate in selecting the government? Are they free to express themselves, associate, and hold governments accountable for results? Is the country politically stable and free from domestic violence, civil strife, war, and terrorism? What is the quality of public services, the civil service, policy formulation, and implementation? Can the government effectively regulate the economy and the private sector? Are rules of law legitimately institutionalised and enforced in courts and by the police? Can countries rein in corruption and prevent state capture by powerful elites for personal gain? Strong governance, particularly public sector management and transparency, are also critical for receiving foreign assistance and allocating it wisely.

These are but a few indicators of governance that the bank is working to study and monitor. The bank has a very important role in working with governments to achieve good governance, but the impetus and action must come from countries themselves. The bank's role is advisory, supportive, financial, and facilitative, not directive. Top-down approaches are unsustainable in the long run.

\section{Structural-level change}

\section{At the country level}

Effectively assisting countries in improving the functioning of political and economic institutions will lay the foundation for countries to pursue the significant structural-level health system changes they require. On the economic front, countries must be able to collect sufficient revenues efficiently, equitably, and sustainably to strengthen their health systems. Revenue collection for the health sector requires a stronger economy and stronger governance so that tax collection and redistribution programmes operate fairly and effectively. Health sector funding is long term and reoccurs over time, so revenue collection systems must be sustainable over the long term. The general public sector budget should have a permanent space for health expenditures.

Countries should also be able to pool risk effectively by having individuals, companies, governments, or a combination of all three, contribute financially to insurance to cover health care when it is needed. Risk pooling for health insurance requires strong regulatory oversight and government policies and programmes. 
On equity grounds, countries should provide all citizens with universal health insurance coverage, and financing should be progressive. WHO's Commission on Macroeconomics and Health estimated it would cost $\$ 34$ per person for countries to cover a basic benefits package for all to achieve the UN Millennium Development Goals.

Countries should also be able to purchase health care goods and services efficiently, whether through provision by the public sector or from the private and non-profit sectors. Although external financing from bilateral and multilateral donors is a good short-term or mediumterm policy to jumpstart a country's health system development, it should be only a temporary solution.

These structural-level changes are built on the broader political and economic institutional improvements noted above and are necessary for sustainable health systems. The bank has an important future part to play in technical policy assistance to governments in policy reform and policymaking, especially in ensuring that critical factors such as equity, efficiency, and sustainability are taken into account. Helping top government officials develop strong leadership skills is also a key bank role.

\section{Changing minds and policy}

\section{Health-system reform}

A political economy of health approach argues for equity in health as essential to improving overall population health. It requires a commitment to social justice. It also recognises that a given country's health policies are social choices made by those in power. Several key principles are important for successful policy reforms at the state level, and the bank, unlike other global health institutions, has a role to play in advising and aiding countries during their reform processes.

First, countries need evidence in the form of scientific and policy knowledge of what works and what does not in health-policy design and implementation. The bank generates and disseminates these global public goods, but it also has a part to play in helping countries build research capacity for their own research programmes. Each country embarking on health-system reform should begin with collecting the existing evidence from the history of their own countries and from lessons learned from other countries. Through its policy analysis, research synthesis, and clearing house capabilities, the bank can shortcut this process for countries and take them step by step through policy reform experiences in other countries. In Mexico, for example, sound evidence helped to make the public aware that health care had become impoverishing. The use of evidence showing outof-pocket expenditures and poverty induced by catastrophic illness raised awareness among the public and focused attention on the issue of financial protection and health-care access. Planners can deploy evidence effectively to make the case for reform. Second, getting health on the policy agenda is also crucial for opening up the possibility of policy reform. Third, efforts to work out the budgetary implications of health reform are key to ensuring adequate spending levels for health. Fourth, reforms in domestic health governance require improving government accountability and reduction of corruption. 


\section{Political will and political processes}

Although significant political will and resulting increases in health financing have occurred globally, the ultimate success of efforts to strengthen health systems requires political will and policy reform at the domestic level. In addition to evidence, capacity building, agenda setting, budgetary planning, and a focus on good governance in the health sector, individuals, groups, and national leaders need to focus on health-system reform, make it a priority, and pursue its achievement. Without the political will, very few reforms will succeed. Generating political will is often a slow, long-term process, much like developing economic programmes. Political processes include several political and institutional factors — political parties, personal politics, legislative policymaking strategies, re-election incentives, financial incentives, civil society or interest groups, and political leadership. In addition to political will and political processes, political windows of opportunity are also essential.

Last, in developing countries in particular, reforms have to acknowledge the severe and seemingly intractable levels of inequality that pervade these economies and the need for strong health-related institutions (think tanks, institutes, medical, nursing, and public-health schools, government entities) to advocate on behalf of those most vulnerable. This makes framing health-policy reform in terms of social justice that much more appropriate.

\section{Norms and values in public policy}

Values and norms are crucial factors in building political support for health-policy reforms. Although principles and beliefs seem abstract and intangible, they do provide an important conceptual framework that affects concrete issues such as illness and the financial means to pay for needed health care. Indeed, planners can weave varying values together to form a coherent basis for policy reform. Ultimately, however, for health-system reform and universal health insurance coverage, people must be willing to pay higher taxes to pay for the health care of others. This policy reality relies on public sentiments of solidarity and equity and individuals' ability to look beyond their own personal situation to collective benefits at the national level, such as increasing financial protection for health-care expenditures. Large-scale social movements and changes in collective policy values resulting in new social and economic trends raise awareness of societal wrongs, such as gross inequities in health. Arguments that challenge norms could be what is necessary in many developing countries to move the public towards consensus on legislative action to ensure health equity for all.

\section{The World Bank in Brazil}

The World Bank can play an important part in the process of value construction and coalition building for collective action. HIV/AIDS in Brazil is a case in point. Through its loans and policy advice, the bank played a part in the Brazilian response to HIV/AIDS, which was built on values of solidarity and human dignity. Through its first project for HIV/ AIDS in 1994, the bank elicited participation from AIDS activists in developing its first AIDS prevention and control loan in Brazil. Over the course of nearly a decade, the development, approval, and implementation of bank projects had a positive effect on the 
work of the National AIDS Program and the activist community. In particular, bank projects provided financial support to the ministry of health for non-governmental organisation (NGO) activities, leading to a proliferation of NGOs, advocacy activities, and greater commitment of financial resources for HIV/AIDS at the national level.

\section{A renewed vision?}

In its new Health, Nutrition, and Population strategy, the World Bank has done a good job of narrowing its focus on specific strengths and comparative advantages. With a few caveats, the bank has hit the nail on the head and now has a renewed vision for the years ahead. The real question is will the bank be able to turn this vision into reality on the ground? The answer depends in part on the bank's ability to practise what it preaches and effectively govern its portfolio in the health sector, improving programme quality and effectiveness. It also depends on governments of developing countries, and on whether countries continue to see the bank as an effective partner in health. Most importantly, however, the bank must make better use of its role in providing policy advice and technical assistance to aid countries not only in building health systems, but also in eliminating their need for bank assistance. After all, the ultimate goal of the bank should be to put itself out of business, to shape a world whose health sectors are sustainable and can function effectively without assistance from the World Bank.

\section{Biography}

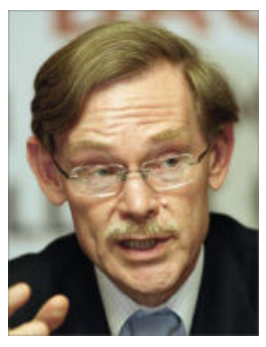

Robert Zoellick took over as president of the World Bank on July 2 
JPR worked previously at the World Bank as health economist in the Health, Nutrition, and Population Sector and as speechwriter to past bank president James D Wolfensohn. She also served on the health and development satellite of former WHO Director-General Gro Harlem Brundtland's transition team. 


\section{Panel: Further reading}

Beyrer C, Gauri V, Vaillancourt D. Evaluation of the World Bank's assistance in responding to the AIDS epidemic: Brazil case study. Washington, DC: World Bank, 2005.

Frenk J. Bridging the divide: global lessons from evidence-based health policy in Mexico. Lancet 2006; 368: 954-61.

Parker R. Building the foundations for the response to HIV/AIDS in Brazil: the development of HIV/AIDS policy, 1982-1996. Divulgacao em Saude Para Debate 2003; 27: 143-83.

Ruger JP. Ethics and governance of global health inequalities. J Epidemiol Community Health 2006; 60: 998-1003.

Ruger JP. Health, capability, and justice: toward a new paradigm of health ethics, policy and law. Cornell Journal of Law and Public Policy 2006; 15: 403-82.

Ruger JP. Toward a theory of a right to health: capability and incompletely theorized agreements. Yale Journal of Law and Humanities 2006; 18: 273-326.

Ruger JP. Rethinking equal access: agency, quality and norms. Global Public Health 2007; 2: 78-96.

Ruger JP. Health, health care, and incompletely theorized agreements: a normative theory of health-policy decision-making. J Health Polit Policy Law 2007; 32: 51-87.

Ruger JP. Moral foundations of health insurance. QJM 2007; 100: 53-57.

Schieber GJ, Gottret P, Fleisher LK, Leive AA. Financing global health: mission unaccomplished. Health Affairs 2007, 26: 921-34. 